\title{
Comparative Study between Single, Double and Intra-Cluster Injection in Ultrasound-Guided Supraclavicular Brachial Plexus Block: A Randomized Trial
}

\author{
SHERIN REFAAT, M.D.; ASHRAF RADY, M.D.; AHMED EL-SONBATY, M.D. and \\ AHMED MAHMOUD, M.Sc.
}

The Department Anesthesiology and Critical Care Medicine, Faculty of Medicine, Cairo University

\begin{abstract}
Background: There are many different approaches for ultrasound-guided supraclavicular brachial plexus block. Each approach has a different success rate and complications.

Aim of Study: The aim of this study is to compare intracluster injection technique compared with the most common supraclavicular approach single and double injection techniques.

Material and Methods: Thirty-six patients received supraclavicular block were divided in to three groups. The total volume of local Anesthetic was $30 \mathrm{ml} 0.5 \%$ bupivacaine, In $\mathrm{Gs}(\mathrm{n}=12)$ the whole volume was injected at corner pocket, while in $\mathrm{Gd}(\mathrm{n}=12)$, half the volume of local anesthetic was injected at corner pocket and the other half was injected supero-lateral to subclavian artery. In Gic $(n=12)$ the whole volume was injected inside main and satellite neural cluster. the onset time was recorded as the primary outcome.
\end{abstract}

Results: Gic showed rapid onset compared to Gs and Gd (8.17 \pm 1.64 minutes, $18 \pm 2.45$ minutes, $12.58 \pm 1.83$ minutes, $p<0.001)$ respectively. While Gd showed the longest duration than Gic and Gs $(444.17 \pm 64.73$ minutes, $310 \pm 50.09$ minutes, $125.83 \pm 43.32$ minutes, $p<0.001)$ respectively. Time of first rescue analgesia was longer in Gd relative to Gic and G s (455 \pm 65.68 minute, $337.50 \pm 49.38$ minutes, $136.67 \pm 49.10$ minutes, $p<0.001)$. Complication was noticed in only one patient in $\mathrm{Gd}$.

Conclusion: Intra-cluster technique for Supra-Clavicular Brachial Plexus Block showed rapid onset with adequate postoperative analgesia and minimal complications.

Key Words: Single injection - Double injection - Intra- cluster injection - Ultrasound guided brachial plexus block.

\section{Introduction}

SUPRACLAVICULAR brachial plexus block (SBPB) can provide an effective surgical anesthesia

Correspondence to: Dr. Sherin Refaat, The Department Anesthesia and Critical Care Medicine, Faculty of Medicine, Cairo University for the forearm and hand. However, the blind technique was associated with many complications; these complications had led to a decline in the usage of this technique. The use of ultrasound had increased SBPB popularity, owing to improved block quality, and had decreased complications $[1,2]$.

There are many different approaches for ultrasound-guided supraclavicular brachial plexus block. Each approach has a different success rate and complications. The most commonly performed ultrasound-guided supraclavicular brachial plexus block is the corner pocket approach (single injection), in which the local anesthetic (LA) is injected at the point where the subclavian artery meets the first rib. The needle in this approach is advanced very close to the subclavian artery and pleura. Therefore, it may be associated with the risk of subclavian artery puncture or pneumothorax [3].

Another technique is the double injection technique, in which half the dose of the local anesthetic is injected in corner pocket and the other half around the main cluster. Other technique is Intracluster technique, done through advancement of the needle tip into the main neural cluster, where half the dose of the local anesthetic is injected inside it and the other half is partitioned into equal aliquots and injected inside each satellite cluster. In this approach, the needle does not have to advance close to the subclavian artery or pleura [4].

In this study, we compared single injection and double injection with the intra-cluster technique for supraclavicular brachial plexus block. We hypothesized that intra-cluster injection technique will be associated with more rapid onset, longer duration, and the least complications (as the trunks 
and divisions of the brachial plexus are relatively close as they travel over the first rib, the anesthesia will be faster and complete).

\section{Patients and Methods}

This study was conducted in Cairo university hospitals from July 2017 to December 2017 after obtaining approval of institutional research ethical committee I.D number (N-34-2017). The study was registered in clinicaltrials.gov registry system with trial number NCT03188939. Written informed consent was taken from 36 patients scheduled for forearm orthopedic procedures. Patients enrolled in the study were aged 18 to 60 years, with body mass index (BMI) of $20-35 \mathrm{Kg} / \mathrm{m}^{2}$ and with ASA physical status I or II. Patients with preexisting neuropathy, previous operation in supraclavicular fossa, coagulopathy, allergy to local anesthetic, pregnancy, or patients who refused the procedure were excluded from the study.

Randomization was performed using computergenerated sequence of random numbers. Concealment was achieved using sealed opaque envelope technique. Patients were randomly allocated into three groups:

- $G s(n=12)$ in which supraclavicular brachial plexus block was done using single injection technique (corner pocket).

- $\mathrm{Gd}(\mathrm{n}=12)$ in which supraclavicular brachial plexus block done using double injection technique (lower corner pocket and superolateral to subclavian artery).

- Gic $(n=12)$ in which supraclavicular brachial plexus block was done using intra-cluster injection technique (half the dose of the local anesthetic is injected inside the main cluster and the other half is partitioned into equal aliquots and injected inside each satellite cluster).

On arrival to the operating room, an 18-gauge peripheral intravenous cannula was placed, and standard anesthesia monitors (Electrocardiography, pulse oximeter, and non-invasive Blood Pressure) were applied. Supplemental oxygen was provided throughout the procedure. Intra-venous premedication $(0.03 \mathrm{mg} / \mathrm{Kg}$ midazolam $)$ was administrated.

Block was performed using 20 gauge $10 \mathrm{~cm}$ block needle and portable ultrasound machine (Siemens ACUSON X300 Ultrasound System with linear probe 8-14 MHZ).

The patient was positioned in the semi-sitting position with the face turned to the contra-lateral side. Proper sterilization of the supraclavicular fossa was performed. After proper surgical draping and displaying the area of the block with the ultrasound probe, local anesthetic (Lidocaine 1\%) was injected. The block needle was inserted in-plane with ultrasound probe after the vascular and nervous structures are optimally visualized. A depth of 3$4 \mathrm{~cm}$ and a frequency of 8-14 MHZ was used.

In the three groups, the ultrasound probe was positioned in the supraclavicular fossa, pointing caudal and moved laterally and medially in order to locate the subclavian artery. The hyperechoic first rib was identified deep to the artery and the pleura was identified and its sliding movement during respiration was noted. The plexus was consistently found with a characteristic "honeycomb" appearance lateral and superficial to the subclavian artery and superior to the first rib.

The needle was introduced through the skin from lateral to medial, in-plane with the transducer, with constant visualization of the needle. The needle directed towards site of injection according to group selected. The local anesthetic solution used in the three groups consisted of $30 \mathrm{ml}$ volumes of bupivacaine $0.5 \%$. This solution was administered in increments with repeated aspiration inbetween and its characteristic distribution around the nerves was observed. (hydro-localization).

In Gs; the bupivacaine was injected at the point where the subclavian artery meets first rib. In Gd; half the volume of bupivacaine $(15 \mathrm{ml})$ was injected at intersection of first rib and subclavian artery and the other half ( $15 \mathrm{ml}$ bupivacaine) was injected supero-lateral to subclavian artery. In Gic; bupivacaine was injected inside main and satellite neural cluster.

After block, the patient was examined for sensory and motor block (every 5 minutes for 30 minutes) and for occurrence of complications e.g. Horner's syndrome. For musculocutaneous, radial, median and ulnar nerves sensory examination, 3 points score was used ( 0 : no block (cold test) 1 : partial block (feeling touch but no cold) 2: Complete block (feeling no cold). The sensory blockade of the musculocutaneous, median, radial, and ulnar nerves was assessed on the lateral aspect of the forearm, the volar aspect of the thumb, the lateral aspect of the dorsum of the hand, and the volar aspect of the fifth finger, respectively. Motor blockade was also graded on a 3-point scale: $(0=$ no block, 1=Paresis, $2=$ =Paralysis). Motor blockade of the musculocutaneous, radial, median, and ulnar nerves was evaluated by elbow flexion, thumb abduction, thumb opposition, and thumb adduction, 
respectively. The maximal composite score was 16 points. We considered the patient ready for surgery when a minimal composite score of 14 points was achieved provided that sensory block score was equal or superior to 7 of 8 points. The time of onset of the block was recorded as a primary outcome. In case of anxiety (as voiced by patients or determined by the treating anesthesiologists), subjects received propofol infusion (25-80 g g/ $\mathrm{kg} / \mathrm{min}$ ) intraoperatively, provided response to verbal stimulus was maintained. In case of pain during surgery, the block was considered failed, and general anesthesia was provided. Duration of sensory block was assessed every 30 minutes after end of surgery and the time of first call for analgesics was recorded by a blind observer. The side effects and complications such as intravascular injection, Horner's syndrome, and pneumothorax were reported.

\section{Sample size:}

Power analysis was performed using one-way analysis of variance (ANOVA) on onset of sensory block because it was the main outcome variable in the present study. A previous study 72 showed standard deviation of sensory block 6.4 minutes in double injection and 8.3minutes in targeted intra cluster injection with mean difference 8.4 minutes between 2 groups [4]. Taking power 0.8 and alpha error 0.025 a minimum sample size of 11 patients was calculated for each group. A total number of patients in each group will be 12 to compensate for possible dropouts.

\section{Statistical analysis:}

Data were coded and entered using the statistical package SPSS version 23. Data was summarized using mean and standard deviation for quantitative variables and frequencies (number of cases) and relative frequencies (percentages) for categorical variables. Comparisons between groups were done using analysis of variance (ANOVA) with multiple comparisons post hoc test (Chan, 2003a). 73 For comparing categorical data, Chi square $\left(\mathrm{X}^{2}\right)$ test was performed. Exact test was used instead when the expected frequency is less than 5 (Chan, 2003b). $74 p$-values less than 0.05 were considered as statistically significant.

\section{Results}

One hundred Forty-two patients were screened for eligibility; one hundred four patients were excluded. Thirty-eight patients underwent randomization. Thirty-eight patients were recruited in the study. Two patient were excluded due to failed block and thirty-six patients were available for final analysis (Fig. 1).

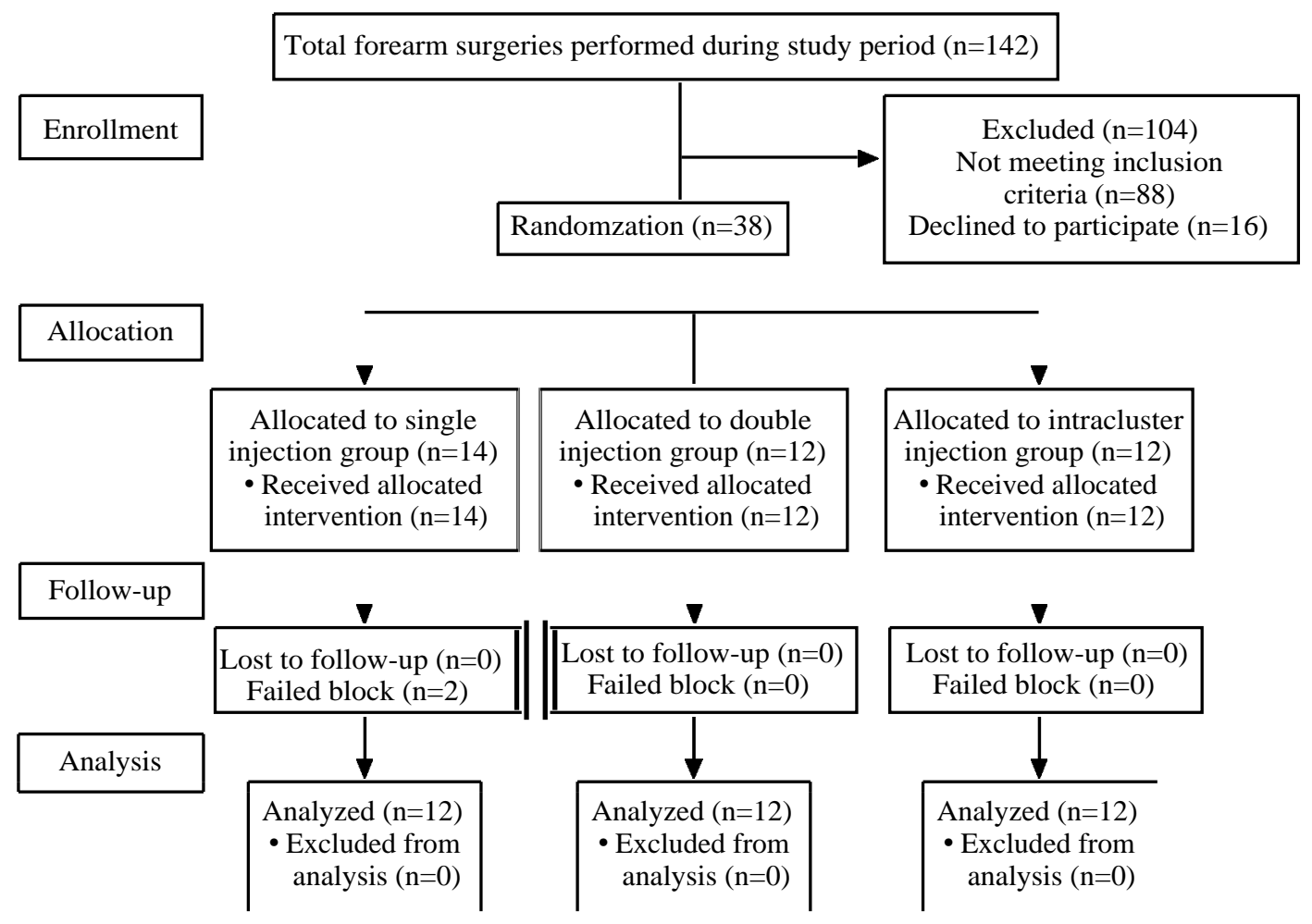

Fig. (1): Flow diagram for the patients in the trial. 
Demographic data was comparable between the three study groups with regard to age, gender, BMI and ASA classification (Table 1).

Table (1): Patients demographic data: Age, Gender, BMI, and ASA classification.

\begin{tabular}{lcccc}
\hline & $\begin{array}{c}\text { Gs group } \\
(\mathrm{n}=12)\end{array}$ & $\begin{array}{c}\text { Gd group } \\
(\mathrm{n}=12)\end{array}$ & $\begin{array}{c}\mathrm{G} \text { ic group } \\
(\mathrm{n}=12)\end{array}$ & $p$-value \\
\hline Age (years) & $28.17 \pm 7.04$ & $27.58 \pm 6.14$ & $26.58 \pm 5.42$ & 0.821 \\
Male Gender & $11(91.7 \%)$ & $10(38.3 \%)$ & $11(91.7 \%)$ & 1 \\
BMI (kg/m $)$ & $24.83 \pm 3.64$ & $24.58 \pm 2.87$ & $24.08 \pm 2.84$ & 0.838 \\
ASA: & & & & \\
In $(\%)$ & $12(100 \%)$ & $12(100 \%)$ & $12(100 \%)$ & - \\
\hline
\end{tabular}

Data are presented as mean \pm standard deviation or frequency $(\%)$

Gic showed shortest onset of sensory block compared to the other two groups. Gd showed shorter onset of sensory block compared to Gs (Table 2), (Fig. 2).

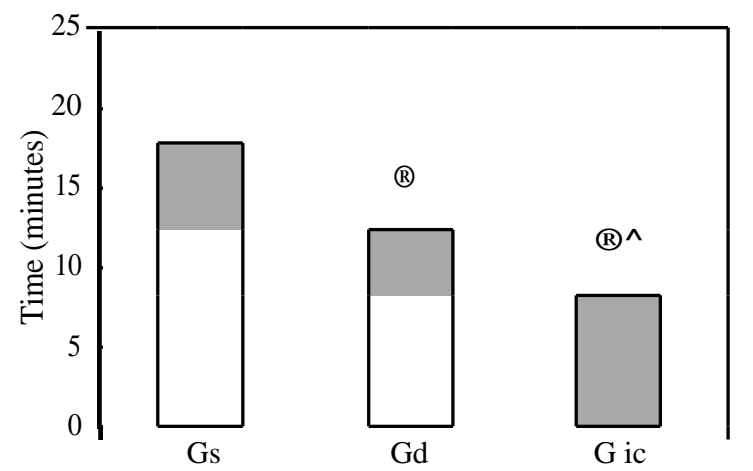

Fig. (2): Onset of the block in minutes.

(B) Statistically significant compared to Gs group $(p<0.05)$.

${ }^{\wedge}$ Statistically significant compared to Gd group $(p<0.05)$

The duration of sensory block was longest in Gd compared to the other two groups.

Gic showed longer duration of sensory block compared to Gs (Table 2).

Regarding time of first rescue analgesics, it was longest in $\mathrm{Gd}$ compared to other groups. Gic showed longer time to first rescue analgesic compared to Gs. (Table 2).

Table (2): Block characteristics. Data are presented as mean \pm standard deviation

\begin{tabular}{|c|c|c|c|c|}
\hline & $\begin{array}{l}\text { Gs group } \\
(\mathrm{n}=12)\end{array}$ & $\begin{array}{c}\text { Gd group } \\
(\mathrm{n}=12)\end{array}$ & $\begin{array}{c}\mathrm{G} \text { ic group } \\
(\mathrm{n}=12)\end{array}$ & $\begin{array}{c}p- \\
\text { value }\end{array}$ \\
\hline $\begin{array}{l}\text { Onset of block } \\
\text { (minutes) }\end{array}$ & $\begin{array}{l}18.00 \pm \\
2.45\end{array}$ & $\begin{array}{l}12.58 \pm \\
1.83 \AA\end{array}$ & $\begin{array}{l}8.17 \pm \\
1.64 \circledast^{\wedge}\end{array}$ & $<0.001$ \\
\hline $\begin{array}{l}\text { Duration of block } \\
\text { (minutes) }\end{array}$ & $\begin{array}{l}125.83 \pm \\
43.32\end{array}$ & $\begin{array}{l}444.17 \pm \\
64.73 \AA\end{array}$ & $\begin{array}{l}310 \pm \\
50.09 \AA^{\wedge}\end{array}$ & $<0.001$ \\
\hline $\begin{array}{l}\text { Time of first rescue } \\
\text { analgesic } \\
\text { (minutes) }\end{array}$ & $\begin{array}{l}136.67 \pm \\
49.10\end{array}$ & $\begin{array}{l}455 \pm \\
65.68 \AA\end{array}$ & $\begin{array}{l}337.50 \pm \\
49.38 \AA^{\wedge}\end{array}$ & $<0.001$ \\
\hline
\end{tabular}

Data are presented as mean \pm standard deviation.

(B) Statistically significant compared to Gs group $(p<0.05)$.

${ }^{\wedge}$ Statistically significant compared to Gd group $(p<0.05)$.
Regarding complications; No complications were detected in Gic nor in Gs. Symptoms of Horner's syndrome were confirmed in one patient in the double injection group but resolved two hours after the block. (Fig. 3).

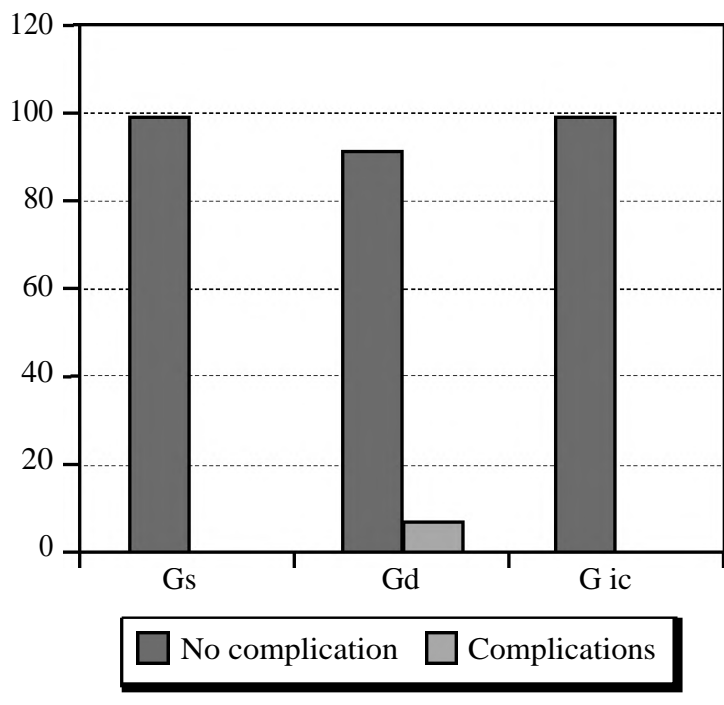

Fig. (3): Incidence of complications in three groups.

\section{Discussion}

In this randomized study, we compared the two commonly used techniques for SCB (single injection and double injection), with the newly introduced intra-cluster injection technique.

Our results showed that Gic had the shortest onset time while Gd recorded the longest duration of sensory block as well as the longest duration of analgesia.

We attribute this rapid onset in Gic to injection inside the main cluster and satellite clusters. The neural tissue is surrounded by layers of connective tissue (the perineurium and epineurium), so the LA takes more time to spread through them and reach the neural tissue. In the intra-cluster technique, the epineurium layer may be penetrated by the needle allowing for a rapid onset. This technique is similar to the usage of sonar-guided block combined with nerve locator for injection nearby the nerve core.

The study done by Techasuk et al., [4], which compared double injection ultrasound-guided supraclavicular block to intra-cluster injection technique, had the same result of our study. The onset time of the block in their study was shorter in Gic (10.1 \pm 6.4 minutes) than $\mathrm{Gd}(18.5 \pm 8.3$ minutes $)$. 
The study done by Tran DQ et al., [5], which compared the single injection and double injection with ultrasound-guided supraclavicular brachial plexus block, recorded that the onset time was shorter in Gd than Gs. This is in consistence with our results.

In this study, the duration of sensory block was longer in Gd and Gic than Gs. In both Gd and Gic, the injection was done in more than one point, which allowed more circumferential and symmetrical spread of LA near the plexus cluster. Another factor is that brachial plexus in supraclavicular region is surrounded by fat (lipophilic), where the LA deposits and is released over the time while in Gs, injection in one point may decrease incidence of adequate spread in all clusters. The duration of block was longer in Gd than Gic, which may be because in intra-cluster technique, the excessive dissection and needle passes lead to loss of some LA, away from the nerve; thus, the total injected dose inside the optimum site was larger in Gd.

Other studies $[\mathbf{6 , 7 , 8 ]}$ recording the duration of the block were comparing different local anesthetics with or without additives or different age groups, but no study compared the duration of different approaches in the same technique.

A study done by Al-Sawy et al., [9] compared the infra-clavicular block and supraclavicular sonar guided block (double injection) and recorded a duration ( 7.4 hours) in $\mathrm{Gd}$ that was similar to $\mathrm{Gd}$ in our results. Another study done by Jadranka Pavičic' Saric et al., [10], comparing single injection supraclavicular ultrasound-guided block in different age groups, showed shorter duration in middleaged patients compared to ours, due to usage of different LA mixture (50\% lidocaine with 50\% bupivacaine).

Regarding duration of sensory block, time of first rescue analgesia was longer in Gd and Gic than Gs. Moreover, time of first rescue analgesia in Gd was longer than in Gic.

Regarding complications, although intra-cluster technique had more needle passes and more manipulations, it did not result in increased complications, as the direction of the needle is away from pleura and vascular structures. However, the sample size was too small to confirm the safety of intracluster injection. In a study done by Techasuk et al., [4], the recorded complications in Gic were the same as those in $\mathrm{Gd}$, and the paresthesia detected was resolved spontaneously within one month.
Limitations: The limitation in this study was the limited number of patients in each group, which did not allow us to detect if the novel intra-cluster block has different incidence of complications than other groups.

Conclusion: Intra-cluster technique for SupraClavicular Brachial Plexus Block showed rapid onset with adequate post-operative analgesia and minimal complications.

This study take approval from institutional research ethical committee I.D number $(\mathrm{N}-34-$ 2017). The study was registered in clinicaltrials.gov registry system with trial number NCT03188939.

Conflict of interest: There is no conflict of interest for any of the authors.

\section{References}

1- TRAN D.Q.H., MUNZO L., ZAOUTER C. and FINLAYSON R.J.: A prospective, Randomized comparison between ultrasound-guided supraclavicular, infraclavicular and axillary brachial plexus blocks. Reg. Anesth. Pain. Med., 34: 366-371, 2009.

2- MORFEY D.H. and BRULL R.: Finding the corner pocket: landmarks in ultrasound-guided supraclavicular block. Anaesthesia, 64: 1381, 2009.

3- DUGGAN E., EL-BEHEIRY H., PERALS A., LIPU M., NUICA A., CHAN V.W., et al.: Minimum effective volume of local anesthetic for ultrasound-guided supraclavicular brachial plexus block. Reg. Anesth. Pain. Med., 34: 215218,2009 .

4- TECHASUK W., GONZALEZ A.P., BERNUCCI F., CUPIDO T., FINLAYSON R.J. and TRAN D.Q.H.: A randomized comparison between double- injection and targeted intracluster injection ultrasound-guided supraclavicular brachial plexus block. Anesth. Analg., 118: 1363-1369, 2014.

5- TRAN D.Q.H., MUNZO L., ZAOUTER C. and FINLAYSON R.J.: A prospective, randomized comparison between single-injection and double-injection ultrasound-guided supraclavicular brachial plexus block. Reg. Anesth. Pain. Med., 34: 420-424, 2009.

6- AHSAN MUSTAFA, KHAJA ALI HASSAN and SYED ABDUR RAHMAN: Comparative study of lignocaine, bupivacaine alone and in combination in supraclavicular block. Indian Journal of Clinical Anaesthesia, 3 (2): 238242, 2016.

7- TRIPATHI D., SHAH K., SHAH C., SHAH S. and DAS E.: Supraclavicular brachial plexus block for upper limb orthopedic surgery: A randomized Double Blinded Comparison between Ropivacaine and Bupivacaine. The Internet Journal of Anesthiology, 30: 4, 2012.

8- PATHAK R.G., ANAND P. SATKAR and RAJENDA N. KHADE: Comparative study of supraclavicular brachial plexus block with and without dexamethasone. Interna- 
tional Journal of Scientific and Research Publication, 2: 12, 2012.

9- AMANY EL-SAWY, NASHWA NABIL MOHAMED, MOHAMED AHMED MANSOUR and MONA RAMADAN SALEM: Ultrasound-guided supraclavicular versus infraclavicular brachial plexus nerve block in chronic renal failure patients undergoing arteriovenous fistula creation. Egyptian Journal of Anesthesia, 30: 2, 2014.

10- JADRANKA PAVICIC SARIC, JELENA ZENKO, VANJA VONICA, TAMARA LUPIS, NATASA PAKLAR and MATEA BOGDANOVIC DVORSCAK: Effect of age on clinical profile of supraclavicular brachial plexus block period. Biol., 117 (2): 287-290, 2015.

\section{دراسة مقارنة عشوائية بين الحقن الأحادى والحقن الثنائى العئي

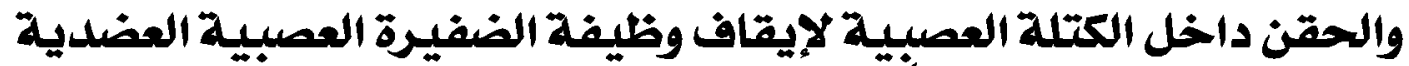

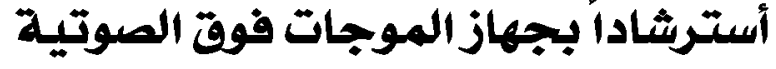

يوجد الكثير من الطرق المختلة لإيقاف وظيفة الضفيرة العبية العضدية أسترشاداً بجهاز الموجات لفقق الصوتية. لكل طريقة من هذه

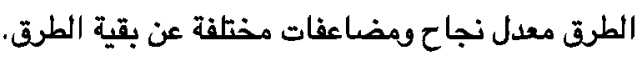

إن هدف هذه الدراسة هو مقارنة الحقن داخل الكتلة العصبية بالحقن الأحادى والحقن الثنائى لإيقاف وظيفة الضفيرة العصبية العضدية. لقد تم إجراء هذه الدراسة في مستشفيات جامعة القاهرة وقد تضمنت ست وثلاثقف مريض يقومف بإجراء جراحات فى الساعد . تم تقسيم المرضى إلى ثلاث مجموعات كل مجموعة تتضمنت أثنى عشر مريض حسب طريقة الحقن. لقد قمنا برصد وتسجيل وتحليل وقت بداية أيقاف

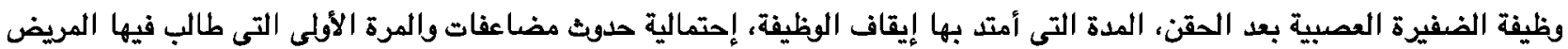
بأخذ مسكن للألم.

وقد أوضحت النتائج أن إستخدام الحقن داخل الكتلة العصبية أسترثـاداً بجهاز الموجات فوق الصوتية أعطى أسرع وقت لبداية إيقاف الوظيفة العصبية وأقل مضاعفات بين الثلاث مجموعات كوبسيلة لتقليل ألم ما بعد جراحات التهات الساعد. 